\title{
EDITORIAL
}

\section{Editorial on 'Hyperglycemia, insulin and slower growth velocity may increase the risk of retinopathy of prematurity' Kaempf JW et al.}

\section{Journal of Perinatology (2011) 31, 228-229; doi:10.1038/jp.2010.158}

Severe retinopathy of prematurity (ROP) is a multifactorial disease characterized by a first phase of impaired growth and obliteration of retinal vessels leading to insufficient vascularization. The second phase of ROP with subsequent pathologic neovascularization may lead to retinal detachment and blindness. While degree of prematurity is decisive, oxygen treatment is the most studied risk factor, which, when poorly controlled, still causes blindness in relatively mature preterm babies. ${ }^{1}$ Recently, poor weight gain during the first weeks of life has been found to be strongly associated with later ROP development, ${ }^{2-4}$ indicating that factors causing impaired general growth also have a negative impact on retinal vessel development.

ROP is a sight-threatening condition of the most immature preterm infants and shares important features with diabetic retinopathy, which is a major cause of visual disability and blindness in adults. Both disorders are characterized by vascular endothelial growth factor (VEGF)-mediated uncontrolled retinal neovascularization under hypoxic conditions. During the last decade, hyperglycemia, the hallmark of diabetes, in the postnatal period of preterm infants has been recognized as a risk factor for ROP as well. ${ }^{5-7}$

In this issue of the Journal of Perinatology, Kaempf $e t$ al. ${ }^{8}$ report the results of a retrospective study of 372 infants born before 30 weeks of gestation, confirming the association between poor weight gain and hyperglycemia during the first postnatal month and later development of ROP. Interestingly, they also report that treatment with insulin is a stronger risk factor than the hyperglycemia per se. As proposed by the authors, proper management guidelines in the first weeks of life, promoting growth while maintaining euglycemia, may be means to reduce ROP.

Poor weight gain is a common problem in very preterm infants, while the genesis is largely unknown. Attempts to reduce ROP by promoting growth through increased nutrition have been only partly successful. ${ }^{9}$ It is difficult to maintain the recommended dietary intake, ${ }^{10}$ and the most immature infants appear to lack the capability to utilize the provided nutrients, partly because of morbidities and medications (for example, steroids). In the study by Kaempf et al., more aggressive nutrition was associated with more hyperglycemia and insulin use, and with a tendency to develop more proliferative ROP.
The hyperglycemia of very preterm neonates has been attributed to both relative insulin resistance and defective islet $\beta$-cell processing of proinsulin. ${ }^{11}$ Insulin-like growth factor I (IGF-I), which is essential for growth in the fetus and neonate, is known to be reduced after very preterm birth and low serum concentrations are associated with ROP. ${ }^{12}$ IGF-I is known to counteract insulin resistance ${ }^{13}$ and it is likely that lack of IGF-I, which possibly can be supplemented, is one factor behind preterm hyperglycemia. The effect of other factors influencing growth in the neonatal period and hence ROP need to be examined further.

The very properly designed study by Kaempf et al. highlights the importance of managing conditions during the first weeks of life to prevent development of proliferative ROP, which develops weeks to months later. It inspires to conduct further research to reveal neonatal factors that may be subjected to interventions in order to prevent ROP. If prevention of neonatal growth restriction can be accomplished, it is plausible that normal development of vascular and neuronal tissues will be promoted (first phase of ROP) and ROP and other morbidities of preterm birth could be prevented. In contrast, much of ROP research today focuses on treatment regimes that block growth factors such as VEGF, aiming at causing established neovascularization to regress (second phase of ROP). Intraocular injections of these extrinsic factors around term has unknown systemic effects in this population of children with already persistent subnormal growth, and impaired development and function of the central nervous system and other tissues. Preventive measures are urgent and the article by Kaempf $e t a l$. shows the direction to start focusing on during the first weeks of life.

\section{Conflict of interest}

Dr Ann Hellström has received compensation as scientific consultant to Premacure $\mathrm{AB}$, and $\mathrm{AH}$ and $\mathrm{A}-\mathrm{LH}$ hold shares in a company controlling Premacure AB.

A Hellström and A-L Hård Department of Ophthalmology, Institute of Neuroscience and Physiology, The Sablgrenska Academy at Gothenburg University, Gothenburg, Sweden E-mail:ann.hellstrom@medfak.gu.se 


\section{References}

1 Shah PK, Narendran V, Kalpana N, Gilbert C. Severe retinopathy of prematurity in big babies in India: history repeating itself? Indian J Pediatr 2009; 76: 801-804.

2 Wallace DK, Kylstra JA, Phillips SJ, Hall JG. Poor postnatal weight gain: a risk factor for severe retinopathy of prematurity. J AAPOS 2000; 4: 343-347.

3 Filho JB, Bonomo PP, Maia M, Procianoy RS. Weight gain measured at 6 weeks after birth as a predictor for severe retinopathy of prematurity: study with 317 very low birth weight preterm babies. Graefes Arch Clin Exp Ophthalmol 2009; 247: 831-836.

4 Hellstrom A, Hard AL, Engstrom E, Niklasson A, Andersson E, Smith L et al. Early weight gain predicts retinopathy in preterm infants: new, simple, efficient approach to screening. Pediatrics 2009; 123: e638-e645.

5 Garg R, Agthe AG, Donohue PK, Lehmann CU. Hyperglycemia and retinopathy of prematurity in very low birth weight infants. J Perinatol 2003; 23: 186-194.

6 Ertl T, Gyarmati J, Gaal V, Szabo I. Relationship between hyperglycemia and retinopathy of prematurity in very low birth weight infants. Biol Neonate 2006; 89: 56-59.

7 Blanco CL, Baillargeon JG, Morrison RL, Gong AK. Hyperglycemia in extremely low birth weight infants in a predominantly Hispanic population and related morbidities. J Perinatol 2006; 26: 737-741.
8 Kaempf JW, Kaempf AJ, Wu Y, Stawarz M, Niemeyer J, Grunkemeier G. Hyperglycemia, insulin and slower growth velocity may increase the risk of retinopathy of prematurity. J Perinatol 2010 (this issue).

9 Drenckpohl D, McConnell C, Gaffney S, Niehaus M, Macwan KS. Randomized trial of very low birth weight infants receiving higher rates of infusion of intravenous fat emulsions during the first week of life. Pediatrics 2008; 122: $743-751$.

10 Embleton ND. Optimal protein and energy intakes in preterm infants. Early Hum Dev 2007; 83: 831-837.

11 Mitanchez-Mokhtari D, Lahlou N, Kieffer F, Magny JF, Roger M, Voyer M. Both relative insulin resistance and defective islet beta-cell processing of proinsulin are responsible for transient hyperglycemia in extremely preterm infants. Pediatrics 2004; 113: $537-541$.

12 Hellström A, Engström E, Hard A-L, Albertsson-Wikland K, Carlsson B, Niklasson A et al. Postnatal serum insulin-like growth factor I deficiency is associated with retinopathy of prematurity and other complications of premature birth. Pediatrics 2003; 112: 1016-1020

13 Clemmons DR. Role of insulin-like growth factor in maintaining normal glucose homeostasis. Horm Res 2004; 62 (Suppl 1): 77-82. 